\section{Os limites da tecnologia na prática médica segundo os princípios da bioética e da ética médica}

\author{
SILVA, Ana Luiza Antony Gomes de Matos da Costa \\ Graduação em Medicina - Centro Universitário de Brasília \\ - UniCEUB/DF. Autor a contatar; e-mail: \\ analuiza.gomesmcs@gmail.com
}

SOUSA, Kamila Catta Preta Carneiro de

Graduação em Medicina - Centro Universitário de Brasília - UniCEUB/DF.

PEREIRA, Gabriela Strini

Graduação em Medicina - Centro Universitário de Brasília

- UniCEUB/DF.

ARAUJO, Ana Carolina Souza Sisnando de

Graduação em Medicina - Centro Universitário de Brasília - UniCEUB/DF.

RIBEIRO, Leonardo Melo Name

Graduação em Medicina - Centro Universitário de Brasília - UniCEUB/DF.

ANDRADE, Isabella Gonçalves

Graduação em Medicina - Centro Universitário de Brasília - UniCEUB/DF.

VIEIRA, Thiago de Lima Vaz

Graduação em Medicina - Centro Universitário de Brasília - UniCEUB/DF.

PALAVRAS CHAVE: Tecnologia; Bioética; Ética médica; Medicina.

INTRODUÇÃO: A bioética surgiu com o intuito de orientar médicos e cientistas na elaboração, manuseio e gestão de recursos para que o rumo das pesquisas, seja centrado no ser humano e na benevolência ${ }^{1}$. Considerando que o papel da bioética em estabelecer uma relação entre a integridade e o estudo das biociências, o avanço científico, mesmo que visando a melhora da medicina, não pode ultrapassar o horizonte da dignidade humana ${ }^{2} \mathrm{O}$ discernimento médico das questões éticas, vai além de apenas um livro de normas que guiam os procedimentos, assimila o respeito ao ser humano e ao seu convívio social, lembrando da essência de liberdade que é um direito das pessoas, sendo então indispensável a responsabilidade ética. Atualmente, com o auge das inovações tecnológicas, buscando atenuar sofrimentos, melhorias estéticas e diminuição das mortes, a tecnologia tem se superado, com novos medicamentos, tratamentos, revoluções na genética de maneira a ajudar na prevenção de doenças e promoção da saúde. No entanto, existem situações em que se deve preservar a identidade pessoal e o estado de terminalidade dos pacientes. Afinal, corre-se o risco de cometer distanásia, prolongando a dor, fazendo uso desnecessário de aparelhos sem benefício a qualidade de vida do paciente e com alto custo ao sistema de saúde ${ }^{3}$. A complexidade das novas tecnologias não se encontra somente na sua constituição. O profissional e pacientes submetidos à utilização de medicamentos e instrumentos carregam com si enorme responsabilidade, pois em ambos existe grande autonomia e vulnerabilidade e cabe, principalmente ao profissional, saber lidar com o equilíbrio entre esses aspectos e, consequentemente, lidar com a aplicação da tecnologia em qualquer intervenção ${ }^{4}$. MÉTODO: Nessa revisão integrativa de literatura, foram selecionados artigos, de 2013 a 2018, nas bases de dados SciELO e Pubmed. Com o intuito de investigar as informações existentes sobre a atuação tecnológica nos sistemas e institutos de saúde. Para, dessa maneira, estabelecer a importância da percepção médica dos momentos em que a tentativa contínua de encontrar mecanismos de tratamento e cura fere a dignidade e a integridade humana. RESULTADOS: É evidente que o corpo humano está em constante evolução e adaptação e com a tecnologia isso não é diferente. As descobertas e inovações tecnológicas, em foco na área de saúde, levantam junto da sua evolução diversas questões a respeito da ética e da sua intervenção no organismo ${ }^{2}$. Mesmo com os avanços na tecnologia tendo extrema importância no mundo da medicina, a partir do momento que se começa a interferir em outra vida faz-se necessária a elaboração não só de um limite, mas de um controle social, econômico e biológico de até que ponto é uma intervenção benéfica para a população. CONCLUSÃO: Dessa forma, conclui-se que e necessária uma avaliação criteriosa da necessidade da utilização de determinadas inovações, buscando manter compromissos de prestação de cuidados de saúde seguros, que tragam paz diminuindo o sofrimento e que sejam aplicados com equidade na sociedade, evitando que o fruto das inovações tecnológicas sejam desfrutados apenas por aqueles que têm os meios de pagar ${ }^{1}$.

AGRADECIMENTOS: Ao Centro Universitário de Brasília (UniCEUB)

\section{REFERÊNCIAS}

[1] F.M.Nogueira, Rev. Bioét. vol.24 no.1 Brasília jan./abr. 2016

[2] I.A.B.Oliveira, Universidade Catolica Portuguesa, Intervenções biotecnologicas no corpo humano.

[3] A.M.P. Saraiva, Rev. Bioét. vol.22 no.1 Brasília jan./abr. 2014

[4] Silva, Bruno Azevedo, et. al., Reflexões sobre bioética, vulnerabilidade e risco: desafios enfrentados pelos pesquisadores. 